\title{
Çocukluk çağı aşılarına yönelik ebeveyn tutumları ölçeğinin Türkçeye kültürel ve dil uyarlaması
}

\author{
Parent attitudes about childhood vaccines scala: Turkish cultural and linguistic \\ validation
}

İrem Akdemir Kalkan, Meryem Merve Ören, Ömer Karaşahin, Yeşim Yıldız, Yakup Demir, Tuba Dal, Fesih Aktar, Selim Badur, Merve Ayhan, Mustafa Kemal Çelen

Gönderilme tarihi:08.06.2020

Kabul tarihi:17.07.2020

\section{Özet}

Amaç: Aşı tereddüdü hem Türkiye hem de dünya için toplumsal tehdit oluşturan bir tutumdur. Bu konuda Türkçeye validasyonu yapılmış bir ölçek bulunmamaktadır. Bu çalışmanın amacı Opel ve ark. tarafından 2011 yılında geliştirilip 2013 yılında revize edilen ve ‘Parent Attitudes About Childhood Vaccines Survey' isimli ölçeğin Türkçeye dil validasyonunun yapılmasıdır.

Gereç ve yöntem: Çalışma bir dil validasyonu çalışması olarak gerçekleştirilmiştir. Opel DJ ve arkadaşları tarafından geliştirilen ölçek için 'Seri yöntem' kullanılarak dil validasyonu çalışması yapılmıştır. Ölçeğin çeviri, gözden geçirme, geri çeviri, açıklığın ve aynıığın değerlendirmesi ile çevirisi sağlanmış ve Modifiye Lawshe yöntemiyle kapsam geçerlilik analizi yapılarak son hali verilmiştir. Uzmanların ölçek maddelerine yönelik içerik uygunluğu yönünden belirtmiş oldukları görüşlere göre her madde için kapsam geçerlilik oranı ve kapsam geçerlilik indeksi hesaplanmıştır.

Bulgular. Tüm ölçek soruları için kapsam geçerlilik oranı kritik değer olan 0,455'in üzerinde saptanmıştır. Ölçeğin kapsam geçerlilik indeksi değeri ise 0,630 olup ölçek sorularının kapsam geçerliliğinin istatistiksel olarak anlamlı olduğu tespit edilmiştir.

Sonuç: Çocukluk çağı aşılarına yönelik ebeveyn tutumları ölçeğinin dil validasyonunun tamamlanması ve kapsam geçerlilik testlerinden istatistik olarak anlamlı sonuçlar alınmış olması bu ölçeğin Türkçe anlaşılırlığının sağlandığını göstermektedir. Sonrasında yapılacak geçerlilik ve güvenilirlik çalışmaları ile ölçeğin Türkiye'de aşı tereddüdü konusunda ebeveyn tutumlarını ölçebilir hale gelmesi hedeflenmektedir. Böylece daha geniş kitlelerde çalışılarak aşı tereddüdü ve mücadelesi konusunda yapılacak çalışmalara katkı sağlayacağı düşünülmektedir.

Anahtar kelimeler: Aşı, aşı tereddüttü, validasyon, ölçek, tutum.

Akdemir Kalkan I, Ören MM, Karaşahin Ö, Yıldız Y, Demir Y, Dal T, Aktar F, Badur S, Ayhan M, Çelen MK. Çocukluk çağı aşılarına yönelik ebeveyn tutumları ölçeğinin Türkçeye kültürel ve dil uyarlaması. Pam Tıp Derg 2021;14:49-56.

\section{Abstract}

Purpose: Vaccine hesitation is a public health threat in Turkey and throughout the world. There is no scale validation inTurkish in this topic. This study sought to validate a Turkish version of the scale developed by Opel et al. in 2011 and revised in 2013, the "Parent Attitudes About Childhood Vaccines Survey".

Materials and methods: This was a translation and linguistic validation study conducted using a serial method. Language validation study was carried out using 'Serial method' for scale developed by Opel DJ and his colleagues. The scale was translated, reviewed, retranslated, and reviewed for clarity and uniformity. Content

İrem Akdemir Kalkan, Dr. Öğr. Gör. Ankara Üniversitesi Tıp Fakültesi Enfeksiyon Hastalıkları ve Klinik Mikrobiyoloji Bölümü, Ankara, Türkiye, e-posta: iremakd@yahoo.com) (orcid.org/0000-0001-5136-9148) (Sorumlu Yazar)

Meryem Merve Ören, Dr. Öğr. Üye. İstanbul Üniversitesi İstanbul Tıp Fakültesi Halk Sağlığı Bölümü, İstanbul, Türkiye, e-posta: meryemmerve@ gmail.com) (orcid.org/0000-0002-3383-7830)

Ömer Karaşahin, Uzm. Dr. Erzurum Bölge Eğitim Araştırma Hastanesi Enfeksiyon Hastalıkları ve Klinik Mikrobiyoloji, Erzurum, Türkiye, e-posta: mrkrshn@gmail.com (orcid.org/0000-0001-7045-1462)

Yeşim Yıldız, Uzm. Dr. Mardin Devlet Hastanesi Enfeksiyon Hastalıkları ve Klinik Mikrobiyoloji, Mardin, Türkiye, e-posta: ysmyldz06@gmail. com) (orcid.org/0000-0003-3006-4112)

Yakup Demir, Arş. Gör. Dr. Dicle Üniversitesi Tıp Fakültesi Enfeksiyon Hastalıkları ve Klinik Mikrobiyoloji Bölümü, Diyarbakır, Türkiye, e-posta: yakupdemir36@gmail.com (orcid.org/0000-0003-2419-3436)

Tuba Dal, Prof. Dr. Ankara Yıldırım Beyazıt Üniversitesi Tıp Fakültesi Tıbbi Mikrobiyoloji Anabilim Dalı, Ankara, Türkiye, e-posta: tuba_dal@ yahoo.com (orcid.org/0000-0002-4245-1534)

Fesih Aktar, Doç. Dr. Dicle Üniversitesi Tıp Fakültesi Çocuk Sağlığı ve Hastalıkları Bölümü Diyarbakır, Türkiye, e-posta: fesihaktar@yahoo.com (orcid.org/0000-0002-0760-5681)

Selim Badur, Prof. Dr. GSK Aşıları İstanbul, Türkiye, e-posta: selim.x.badur@gsk.com (orcid.org/0000-0002-0490-7203)

Merve Ayhan, Serbest Eczacı, Batman, Türkiye, e-posta: eczmervee@outlook.com (orcid.org/0000-0003-3145-4059)

Mustafa Kemal Çelen, Prof. Dr. Dicle Üniversitesi Tıp Fakültesi Enfeksiyon Hastalıkları ve Klinik Mikrobiyoloji Bölümü, Diyarbakır, Türkiye, e-posta: mkcelen@hotmail.com (orcid.org/0000-0001-5876-2241) 
validity was assessed using a modified Lawshe method. A content validity ratio and content validity index was calculated for each item according to the opinions expressed regarding the suitability of each scale item.

Results: The scope validity ratio for all questions was above the critical content validity ratio of 0.455 . The content validity index value of the scale was 0.630 , and the content validity of the questions was statistically significant.

Conclusions: The linguistic validation of the parental attitude scale regarding childhood vaccination and the statistically significant results of the scope validity tests indicate that the Turkish version is valid. Subsequent validity and reliability studies are expected to make the scale measuring parental attitudes about vaccine heed in Turkey.Thus, it is thought that it will contribute to the studies to be carried out on vaccine heed and struggle by working in a wider audience.

Key words: Vaccine, vaccine hesitation, validation, scale, attitude.

Akdemir Kalkan I, Oren MM, Karasahin O, Yildiz Y, Demir Y, Dal T, Aktar F, Badur S, Ayhan M, Celen MK. Parent attitudes about childhood vaccines scala: Turkish cultural and linguistic validation. Pam Med J 2021;14:49-56.

\section{Giriş}

Aşı tereddüdü, Dünya Sağlık Örgütü (DSÖ) tarafından aşılama hizmeti olmasına rağmen kişilerin aşıyı yaptırmayı ertelemesi ya da reddetmesi olarak tanımlanmıştır [1]. Aslında, toplumlarda aşının keşfinden bu yana süregelen bir davranıştır. Türkiye'de ise 2016 yılında yüzde 98 olan aşılama oranı, 2017 yılında yüzde 96'ya gerilemiştir. Çocuklarına aşı yaptırmak istemeyen ebeveynlerin sayısı; 2011'de 183 iken, 2016'da 12 bin düzeyine yükselmiş ve 2018 yılı itibari ile yirmi üç bin düzeyine ulaştığı bildirilmiştir. Bu durum, ülkemizde kızamık insidansında 2016'dan günümüze on kat artış ile sonuçlanmıştır [2].

Toplum bağışıklaması kavramının öneminin anlaşılması ve aşıyla önlenebilir hastalıkların artışı nedeniyle, aşı tereddütünü Dünya Sağlık Örgütü (DSÖ) 2019'da çözüme kavuşturmayı planladığı on küresel sağlık sorununun arasına almıştır [3, 4]. Türkiye'de ise 2015 yılında açılan bir dava sonucu, bebek ve çocuklara aşı uygulanması için ebeveyn onam gerekliliği gündeme gelmiştir, bu da ebeveynlerin aşıya karşı tutumlarını daha belirleyici bir noktaya taşımıştır [5].

Aşı yaptırmama konusunda ortaya çıkan bu artış ile birlikte aşı tereddüdü nedenlerinin ortaya konması, standart bir ölçüm aracı kullanılarak ailelerin aşıya karşı tutumlarının belirlenmesi ve bu artışı durdurmak için çözümlerin geliştirilmesi önem kazanmıştır. Son yıllarda, dünya genelinde, aşı tereddüdünün boyutunu ortaya koymak ve nedenlerini tanımlayarak bunları ortadan kaldırmaya yönelik adımları belirlemek için çalışmalar yapılmaktadır [6]. Aşı tereddüdüne yönelik çalışmalarda toplumun her kesimine ulaşması hedeflenmektedir. Son 10 yıl içerisinde, farklı ülkelerde ve farklı gruplarda, aşı kararsızlığı nedenlerini araştıran anket ve ölçek temelli gözlemsel çalışmalar yapılmıştır [7-9]. Ancak, valide edilen her ölçekte gelişime açık yönler bulunmaktadır. Bu nedenle henüz tüm dünya genelinde aşı tereddüdünün nedenlerini her yönüyle irdeleyen kabul edilmiş bir anket veya ölçek bulunmamaktadır. Bu çalışmanın amacı Opel ve ark. [10-12] tarafından 2011 yılında geliştirilip 2013 yılında da revize edilen ve 'Parent Attitudes About Childhood Vaccines Survey' isimli ölçeğin Türkçeye dil validasyonunun yapılmasıdır.

\section{Gereç ve yöntem}

$\mathrm{Bu}$ çalışma bir dil validasyonu çalışması olarak gerçekleştirilmiştir. Çalışmada öncelikle Pubmed, Google, Google Scholar veri tabanları taranmıştır. İncelenen ölçekler içerisinde, ölçme değerlendirme gücü açısından soruları Türkiye için uygulanabilir bulunan Opel DJ. ve ark.'nın [10-12] ölçek çalışması validasyon amacıyla seçilmiştir. Opel DJ.'den elektronik posta yolu ile ölçeğin çalışmada kullanılması amacıyla izin alınmıştır (Ek-1). Sonrasında Dicle Üniversitesi Tıp Fakültesi Girişimsel Olmayan Araştırmalar Etik Kurulu'nun onayı ile çalışma başlatılmıştır.

Validasyon yöntemi olarak 'Seri Yöntem' metodu uygulanmıştır, çeviri aşamaları Şekil 1 'de özetlenmiştir. Çalışmanın ilk adımında ölçek, çalışmayı yapan araştırıcı grubundaki beş hekim (üç enfeksiyon hastalıkları, bir pediatri ve bir halk sağlığı uzmanı) tarafından ana dilden (İngilizce) hedef dil Türkçeye çevrilmiştir. Daha sonrasında yapılan çeviriler üzerinden puanlama yapılması ve en uygun çevirinin seçilebilmesi amacıyla, grup üyeleri dışında anadili Türkçe 
olan ve İngilizce dilinde yetkin, hekim olmayan beş kişiye anonim dosya olarak iletilmiş ve her soruyu 1-5 arasında puanlamaları istenmiştir. Yapılan puanlama sonucu, en yüksek ilk iki puanı alan çeviriler araştırmacılar tarafından seçilerek, çeviriler tekrar gözden geçirilmiştir. $\mathrm{Bu}$ şekilde bir ölçek formu hazırlanmıştır. Dil validasyonunun son aşamasında anadili İngilizce olan ve akıcı şekilde Türkçe konuşan profesyonel bir tercüman tarafından Türkçe çeviri İngilizceye geri çevrilmiştir. Bu geri çeviri dosyası hem profesyonel tercüman hem de Opel DJ tarafından aslını yansıtmak konusunda onaylanmıştır. Ölçek sorularına ek olarak yaş, cinsiyet, medeni durum vb. özelliklerin sorgulandığı demografik sorular da ölçek formuna eklenmiştir.

Çalışmaya demografik verileri kaydedilen ve aydınlatılmış onamı alınan, iki yaşın altında en az bir çocuğu olan, 18 yaşın üzerindeki Türkiye'nin beş farklı ili Ankara, Diyarbakır, Erzurum, İstanbul, Mardin'den seçilen 25 ebeveyn (18 anne ve 7 baba) dâhil edilmiştir.
Açıklık ve aynılığın değerlendirilmesi amacıyla, çalışmaya alınan ebeveynlere yüz yüze görüşme yöntemiyle ölçek uygulanmıştır. Ölçekte, ebeveynlerin sorulan her bir soru için cevap vermesi beklenmiş ve sonrasında sorunun anlaşılırlığını ölçmek amacıyla 'Bu soru yeterince anlaşılır mı?' 'Eğer anlaşılmaz ise hangi noktası anlaşılmaz?' 'Daha anlaşılır olması için önerileriniz nelerdir?' şeklinde üç soru daha yöneltilmiş ve her bir soru için önerileri kaydedilmiştir. Ölçek sorularının ardından kişilere tüm ölçek için 'Ölçeğin öncesinde size yapılan açıklama yeterli miydi? 'Bu ölçek sizce doldurulması kolay bir ölçek mi?' 'Ölçeğin genelinde sizi olumsuz etkileyen bir kelime/kelimeler soru/sorular var mıydı?' 'Cevap seçenekleri soru kökünü yansıtmak için yeterince uygun muydu?' başlıkları ile ölçeğin tümünü değerlendirmeye yönelik dört soru yöneltilmiştir. Ölçeği uygulayan araştırmacılar tarafından kişilerin verdiği cevaplar içerisinde önemli olarak saptanan cümleler araştırmacılar tarafından not alınmıştır. Tüm bu basamakların ardından ölçeğe son hali verilmiştir (Şekil 1).

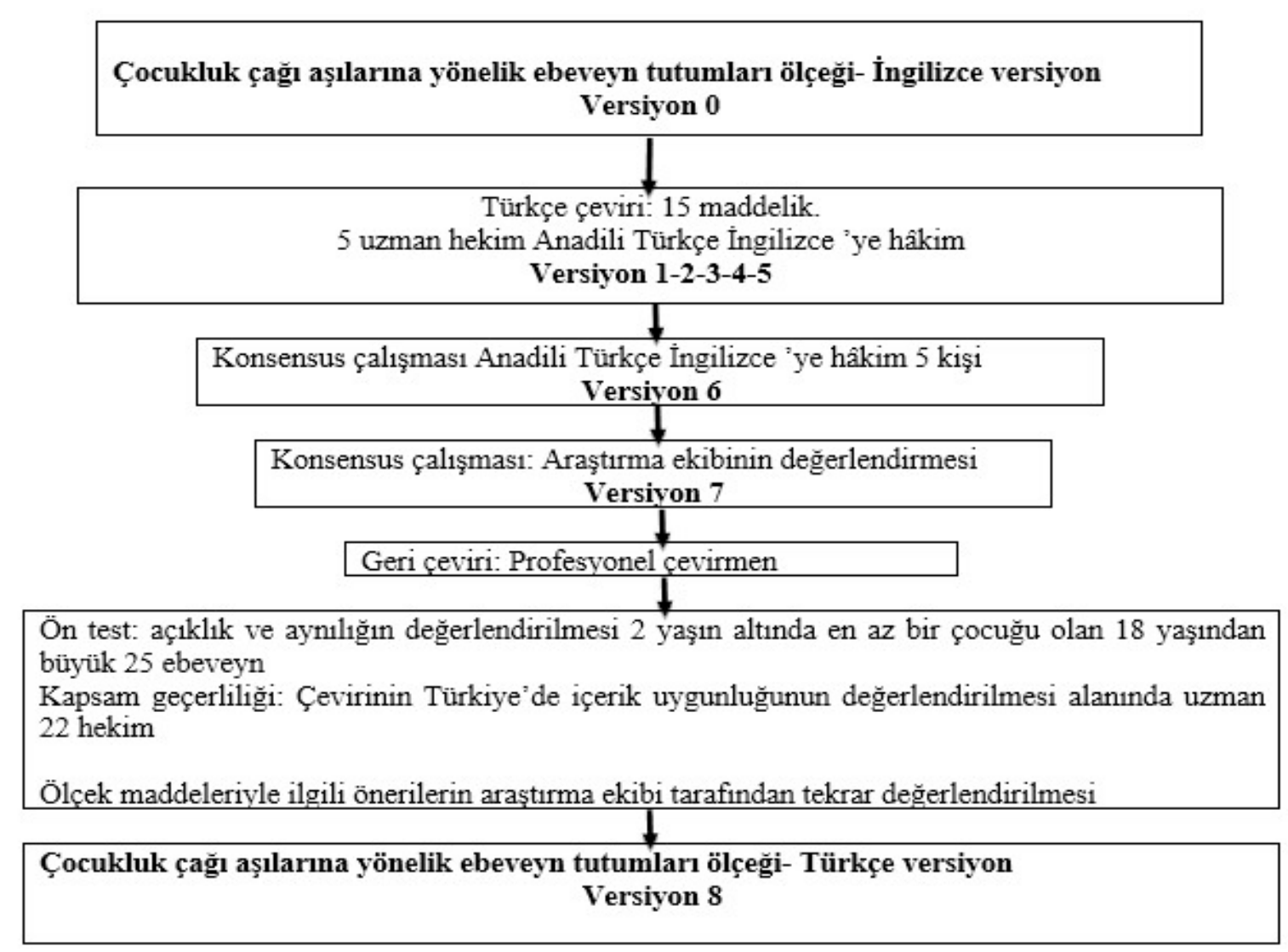

Şekil 1. Çocukluk çağı aşılarına yönelik ebeveyn tutumları ölçeğinin çeviri basamakları 
Kapsam geçerlilik tespitinde sonuçların nesnelliğinin sağlanabilmesi için 5-40 arasında uzman ile değerlendirilmesi literatürde önerilmektedir [13]. Bu bilgiden yola çıkarak kapsam geçerlilik analizi yapılması amacıyla ölçek 7 halk sağlığı uzmanı, 9 enfeksiyon hastalıkları ve klinik mikrobiyoloji uzmanı ve 6 çocuk sağlığı ve hastalıkları uzmanı olan toplam 22 uzman hekime iletilmiştir. Bu kişilere çalışma süreci hakkında bilgi verilerek 15 soruyu soru içeriklerinin uygunluğu, ölçülmek istenen alanı karşılama durumu açısından değerlendirmeleri istenmiştir.

$\mathrm{Bu}$ kişilerin cevapları Modifiye Lawshe yöntemiyle kapsam geçerlilik analizi yapılarak değerlendirmiştir. Verilerin analizinde tanımlayıcı istatistik yöntemler, kapsam geçerlik oranı (KGO) ve kapsam geçerlik indeksleri (KGI) kullanılmıştır. KGO değerinin istatistiksel olarak anlamlılığı için kullanılan kapsam geçerlilik ölçütü değeri (veya KGO minimum/kritik değeri) 22 uzman varlığında 0,455 olarak belirlenmiştir. Çalışma sonucunda elde edilen KGI değerinin kapsam geçerlilik ölçütü değerinden büyük olması ölçekte bulunan maddelerin kapsam geçerliliğinin istatistiksel olarak anlamlı olduğunu gösterir [13, 14]. Bu çalışma ölçek seçimi işleminden itibaren Nisan 2019'da başlamış olup dil validasyonu süreci Temmuz 2019'da tamamlanmıştır. Ölçeğin orijinal soruları Tablo 1'de verilmiştir.

Tablo 1. Parent attitudes about childhood saccines survey [10]

1. Have you ever delayed having your childget a shot (not including seasonal fluors wine flu (H1N1) shots) forreasonsotherthanillnessorallergy? (Yes, No, Don'tKnow)

2. Have you ever decided not to have your child get a shot (not including seasonal fluors wine flu (H1N1) shots) for reason so the rthanillnes so rallergy? (Yes, No, Don'tKnow)

3. How sure are you that following there commended shots chedule is a good idea for your child? Please answer on a scale of 0 to 10 , where 0 is Not at all sureand 10 is Completely sure.

4. Children get more shots than are good for them.

(Strongly Agree, Agree, Not Sure, Disagree, Strongly Disagree)

5. I believe that many of the illnesses that shots preventare severe. (Strongly Agree, Agree, Not Sure, Disagree, Strongly Disagree)

6. It is better formy child to develop immunity by getting sick than to get a shot. (Strongly Agree, Agree, Not Sure, Disagree, Strongly Disagree)

7. It is better for children to get fewer vaccines at the same time.

(Strongly Agree, Agree, Not Sure, Disagree, Strongly Disagree)

8. How concerned are you that your child might have a serious side effect from a shot?

(Not at all Concerned, Not too Concerned, Not Sure, Some what Concerned, Very Concerned)

9. How concerned are you that any one of the childhood shots might not be safe?

(Not at all Concerned, Not too Concerned, Not Sure, Some what Concerned, Very Concerned)

10. How concerned are you that a shot might not prevent the disease?

(Not at all Concerned, Not too Concerned, Not Sure, Some what Concerned, Very Concerned)

11. If you had another infant today, would you want him/her toget all there commended shots? (Yes, No, Don't Know)

12. Over all, how hesitant about childhood shots would you consider your self to be? (Not at all Hesitant, Not too Hesitant, Not Sure, Some what Hesitant, Very Hesitant)

13. I trust the information I receive about shots.

(Strongly Agree, Agree, Not Sure, Disagree, Strongly Disagree)

14. I am able too penly discuss my concerns about shots with my child's doctor. (Strongly Agree, Agree, Not Sure, Disagree, Strongly Disagree)

15. All things considered, how much do you trust your child's doctor?

Please answer on a scale of 0 to 10 , where 0 is Do not trust at all and 10 is Completely trust. 


\section{Bulgular}

İlk çeviri ve uzman değerlendirmesi sonrası (versiyon 8) ölçek soruları (Tablo 2) ebeveynlere yöneltilmiştir.

Çalışmaya dahil edilen ebeveynlerin yaş ortalaması $31,6 \pm 5,6$ olup tamamı evli olarak tespit edilmiştir. Aşılar ile ilgili olumsuz deneyimi olduğunu belirten bir kişi olup "Kardeşim karma aşıdan sonra havale nöbetleri geçirmeye başladı ve ondan sonra zihinsel engeli oldu" ifadesiyle bu deneyimini belirtmiştir. Çalışmaya katılanların demografik bilgileri Tablo 3'te sunulmuştur.

Ölçek sorularıyla ilgili olarak katılımcıların anket soruları anlaşılır bulma durumları Tablo 4 'te belirtilmiştir.

Tablo 2. Çocukluk çağı aşılarına yönelik ebeveyn tutumları ölçeği

1.Çocuğunuzun aşısını hastalık ya da alerji dışında bir nedenle hiç ertelediniz mi? (Evet, Hayır, Bilmiyorum)

2.Çocuğunuzun aşısını hastalık ya da alerji dışında bir nedenle yaptırmadığınız oldu mu? (Evet, Hayır, Bilmiyorum)

3.Ülkemizde ücretsiz olarak uygulanmakta olan aşı takviminin çocuğunuz için uygun olduğuna ne kadar eminsiniz 0'dan 10'a kadar bir puan ile değerlendiriniz.

(0 hiç emin değilim 10 tamamen eminim)

4. Çocukların gereğinden fazla aşı olduğunu düşünüyorum. (Kesinlikle Katılıyorum, Katılıyorum, Kararsızım, Katılmıyorum, Kesinlikle Katılmıyorum)

5.Aşılar sayesinde birçok ağır hastalığın önlendiğini düşünüyorum. (Kesinlikle Katılıyorum, Katılıyorum, Kararsızım, Katılmıyorum, Kesinlikle Katılmıyorum)

6. Çocuğumun hastalığı geçirerek bağışıklık kazanması aşıdan daha iyidir. (Kesinlikle Katılıyorum, Katılıyorum, Kararsızım, Katılmıyorum, Kesinlikle Katılmıyorum)

7. Çocukların bir seferde daha az sayıda aşı olması daha iyidir. (Kesinlikle Katılıyorum, Katılıyorum, Kararsızım, Katılmıyorum, Kesinlikle Katılmıyorum)

8. Aşı sonrası çocuğunuzda ciddi bir yan etki olmasından endişe ediyor musunuz? (Çok Endişeleniyorum, Endişeleniyorum, Kararsızım, Endişelenmiyorum, Hiç Endişelenmiyorum)

9. Çocukluk çağı aşılarından herhangi birinin güvenli olmadığından endişeleniyor musunuz? (Çok Endişeleniyorum, Endişeleniyorum, Kararsızım, Endişelenmiyorum, Hiç Endişelenmiyorum)

10. Çocukluk çağında yapılan aşılardan herhangi birinin hastalığı önlemeyeceği ile ilgili endişeleniyor musunuz? (Çok Endişeleniyorum, Endişeleniyorum, Kararsızım, Endişelenmiyorum, Hiç Endişelenmiyorum)

11. Bugün başka çocuğunuz olsa onun önerilen tüm aşıları olmasını ister miydiniz? (Evet, Hayır, Bilmiyorum)

12.Genel olarak, çocukluk çağı aşıları hakkında ne kadar endişe ediyorsunuz? (Çok Endişeleniyorum, Endişeleniyorum, Kararsızım, Endişelenmiyorum, Hiç Endişelenmiyorum)

13. Aşılar hakkında aldığım bilgilere güveniyorum. (Kesinlikle Katılıyorum, Katılıyorum, Kararsızım, Katılmıyorum, Kesinlikle Katılmıyorum)

14. Çocuğumun doktoruyla aşılar hakkındaki endişelerimi açıkça tartışabiliyorum. (Kesinlikle Katılıyorum, Katılıyorum, Kararsızım, Katılmıyorum, Kesinlikle Katılmıyorum)

15. Her şeyi değerlendirdiğinizde çocuğunuzun doktoruna ne kadar güveniyorsunuz 0 ile 10 arasında bir puanla değerlendiriniz. (0 hiç güvenmiyorum 10 tamamen güveniyorum) 
Tablo 3. Kişilerin demografik özellikleri ve aşı ile ilgili bilgi kaynaklarının dağılımı

\begin{tabular}{lll}
\hline & Sayı & Yüzde (\%) \\
\hline Eğitim durumu & 4 & 16,0 \\
İlkokul & 2 & 8,0 \\
Ortaokul & 5 & 20,0 \\
Lise & 14 & 56,0 \\
Üniversite ve üzeri & & \\
Gelir algısı & 8 & 32,0 \\
Gelirim giderimden az & 7 & 28,0 \\
Gelirim giderimden fazla & 10 & 40,0 \\
Gelirim giderime denk & $4(3-7)$ & \\
Evde yaşayan kişi sayısı & & \\
Aşı ile ilgili bilgi kaynağı & 15 & 60,0 \\
Doktor & 13 & 52,0 \\
Diğer sağlık çalışanı & 11 & 44,0 \\
Medya & 4 & 16,0 \\
Gazete & 4 & 16,0 \\
Bilimsel kaynak & 3 & 12,0 \\
Sağlık bakanlığı & 3 & 100,0 \\
Komşu & 25 & \\
Toplam & & \\
\hline & & \\
& &
\end{tabular}

Tablo 4. Katılımcıların anket soruları anlaşıı bulma durumları

\begin{tabular}{lll}
\hline & Sayı & Yüzde \\
\hline 1.Çocuğunuzun aşısını hastalık ya da alerji dışında bir nedenle hiç ertelediniz mi? & 25 & 100,0 \\
2.Çocuğunuzun hastalıkta da alerji dışında bir nedenle aşısını yaptırmadığınız oldu mu? & 25 & 100,0 \\
3.Bugün başka çocuğunuz olsa onun önerilen tüm aşıları olmasını istermiydiniz? & 25 & 100,0 \\
4. Sağlık bakanlığı tarafından önerilen aşı takviminin çocuğunuz için uygun olduğuna & 25 & 100,0 \\
ne kadar eminsiniz 0'dan 10'a kadar bir puan ile değerlendiriniz. (0 hiç emin değilim 10 & \\
tamamen eminim) & 14 & 56,0 \\
5.Çocuklar kendileri için iyi olandan daha fazla aşı olmaktadır. & 25 & 100,0 \\
6. Aşılar sayesinde birçok ağır hastalığın önlendiğini düşünüyorum. & 24 & 96,0 \\
7.Çocuğumun hastalığı geçirerek bağışıklık kazanması aşıdan daha iyidir. & 21 \\
8.Çocukların aynı anda daha az sayıda aşı olması daha iyidir. & 84,0 \\
9.Aşılar hakkında aldığım bilgilere güveniyorum. & 24 \\
10.Çocuğumun doktoruyla aşılar hakkındaki endişelerimi açıkça tartışabiliyorum. & 96,0 \\
11. Her şeyi değerlendirdiğinizde çocuk doktorunuza ne kadar güveniyorsunuz 0 ile 10 & 24 & 96,0 \\
arasında bir puanla değerlendiriniz. (0 hiç güvenmiyorum 10 tamamen güveniyorum) & 25 \\
12.Aşı sonrası çocuğunuzda ciddi bir yan etki olacağıyla ilgili endişeleniyormusunuz? & 100,0 \\
13. Çocukluk çağı aşılarından herhangi birinin güvenli olmadı̆̆ına dair ne kadar & 23 \\
endişeleniyorsunuz? & 92,0 \\
14. Bir aşının hastalığı önlemeyebileceği konusunda ne kadar endişelisiniz? & 23 \\
15. Genel olarak, çocukluk çağı aşıları hakkında ne kadar tereddüt ediyorsunuz? & 92,0
\end{tabular}


Çalışmaya katılan ebeveynlerden 22'si (\%88) genel olarak ölçeğin doldurulmasının kolay olduğunu, ölçek öncesi açıklamanın yeterli ve anlaşılır olduğunu ifade etmiştir. Aynı zamanda sorular içerisinde rahatsız eden herhangi bir nokta olmadığı ve sorular için kullanılan cevap seçeneklerinin yeterli olduğu belirtilmiştir. Toplamda 22 uzmanın maddelere yönelik içerik uygunluğu yönünden belirtmiş oldukları görüşlere göre her madde için KGO'ları hesaplanmıştır. Tüm ölçek soruları için KGO kritik değer olan 0,455'in üzerinde saptanmıştır. KGI değeri ise 0,630 olup ölçek sorularının kapsam geçerliliğinin istatistiksel olarak anlamlı olduğu tespit edilmiştir.

\section{Tartışma}

Aşı uygulamaları, hastalıklardan korunmanın en uygun ve maliyeti düşük yollarından biridir [3]. Aşılama bireysel bağışıklığını sağlandığından ve toplum sağlığının korunduğundan 20. yüzyılın en önemli ve en etkili halk sağlığı uygulamalarındandır.

Aşı tereddüdü dünyada bazı tehlikeli hastalıkların artışına, çocukların gereksiz yere acı çekmesine, morbiditeye, mortaliteye ve sınırlı halk sağlığı kaynaklarının israfına yol açmaktadır [3, 4, 15]. Aşıların olumsuz sağlık sonuçlarıyla zamansal tesadüfi ilişkileri, bireylerin aşı ile önlenebilir hastalıklara aşina olması, şirketler ve kamu sağlık kuruluşlarına duyulan güvensizlik ve aşının zorunlu içerikleri gibi faktörler aşı tereddüdünün nedenleri arasında sayılmaktadır. Ebeveynlerin aşıya karşı tutumları birbirinden farklı ve heterojendir. Aşıların uygulanmasına tamamıla karşı olanlar, uygulama yolları ve zamanlamasıyla ilgili kaygı yaşayanlar, uygulanma zamanlarını geciktirenler, güvenliğinden endişe edenler, uygulanması gerektiğini düşünen ama içeriğinden endişe edenler veya güvenilir bilgilere sahip olamadıklarından endişe edenler bu heterojen grubun belli başlı alt gruplarını oluşturmaktadır [3, 9]. Aşı tereddüdünün çok faktörlü ve karmaşık nedenlerinden dolayı, aşı tereddüdü ile mücadelede toplumu, sağlık profesyonellerini, sağlık sistemini içeren, ulusal ve uluslararası düzeyde çok paydaşlı geniş bir yaklaşıma intiyaç duyulmaktadır [3]. Ebeveynlerin aşı tereddütlerinin nedenini belirlemek, endişelerini ve güven eksikliği konularını daha iyi anlamak için standardize edilmiş ölçekler kullanılmaktadır. Literatürde aşı tereddüdü konusunda ebeveyn tutumlarını ölçen Türkçe hazırlanmış, geçerlilik güvenirlik analizi yapılmış ebeveyn tutumlarını ölçen bir ölçek bulunmamaktadır. Yine aynı şekilde başka bir dilden Türkçeye validasyonu yapılmış aşı tereddüdü/kararsızlığı durumunu tespit eden bir ölçek de bulunmamaktadır. Bu amaçla uyarlaması yapılmış olan bu ölçek, çocukluk çağı aşılarına ebeveyn tutumlarını ölçmeye yönelik bir ölçeğin Türkçe' ye uyarlandığı ilk çalışmadır.

Çalışmada tüm ölçek soruları için KGO değeri, kritik değer olan 0,455'in üzerinde saptanmıştır. Kapsam geçerlik indeksleri değeri ise 0,630 olarak belirlenmiş olup ölçek sorularının kapsam geçerliliğinin istatistiksel olarak anlamlı olduğu tespit edilmiştir. Çalışmamızda hedef dile çeviri sonrası 25 ebeveyne uygulanan ankette 'Çocuklar kendileri için iyi olandan daha fazla aşı olmaktadır' en az (\%56) anlaşılır madde olarak dikkat çekmiştir. Bu maddede aynı ölçeğin İspanyolca' ya uyarlamasında da uyumsuzluk ve okunabilirlik sorunları tespit edilmiştir [16]. "Bir aşının hastalığı önlemeyebileceği konusunda ne kadar endişelisiniz?" sorusunu ise ebeveynlerin \%68'i anlaşılır bulmuştur. Diğer sorular ise \%81'in üzerinde ebeveynler için anlaşılır bulunmuştur. Ancak soruların anlaşılırlığı genel olarak değerlendirildiğinde, çocukluk çağı aşılarına yönelik ebeveyn tutumları ölçeğinin dil validasyonunun tamamlanması sonrasında kapsam geçerlilik testlerinden istatistiksel olarak anlamlı sonuçlar alınmış olması, bu ölçeğin Türkçe anlaşılırlığının sağlandığını göstermektedir.

Sonuç olarak, çalışmada kullanılan ölçeğin kapsam geçerliliği sağlanmıştır. Çalışmamızın en önemli kısıtlılığı ölçeğin anlaşılırlığı düşük olan iki soru içermesi olup anlaşılırlığı artırmak için soruların yüz yüze görüşme yöntemiyle sorularak cevapların alınması önerilebilir. Ayrıca çalışmada kullandığımız ölçeğin Türkiye'de ebeveynlerin aşı tereddüdü konusundaki tutumlarını ölçebilir hale gelmesi için uygun çalışma grubunda geçerlilik ve güvenilirlik analizlerinin yapılması gerekmektedir. Çalışmada sunulan ölçeğin daha geniş kitlelerde çalışılması, aşı tereddüdü ve mücadelesi konusunda yapılacak çalışmalara katkı sağlayacaktır.

Çıkar ilişkisi: Yazarlar çıkar ilişkisi olmadığını beyan eder. 


\section{Kaynaklar}

1. MacDonald NE, SAGE WorkingGroup on VaccineHesitancy. Vaccinehesitancy: definition, scopeanddeterminants. Vaccine 2015;33:4161-4164. https://doi.org/10.1016/j.vaccine.2015.04.036

2. Gür E. Aşı kararsızlığı-aşı reddi. Turk Pediatri Ars 2019;54:1-2. https://doi.org/10.14744/ TurkPediatriArs.2019.79990

3. Dubé E, Laberge C, Guay M, Bramadat P, Roy R, Bettinger JA. Vaccine hesitancy: an overview. Hum Vaccin Immunother 2013;9:1763-1773. https://doi. org/10.4161/hv.24657

4. World Health Organization. Ten threats to globa Ihealth in 2019. Available from: https://www.who.int/ emergencies/ten-threats-to-global-health-in-2019. Accessed October 27, 2019

5. Çapanoğlu E. Sağlık çalışanı ve ebeveyn perspektifinden çocukluk çağı aşılarının redid niteliksel bir araştırma. Acıbadem Üniversitesi Sağlık Bilimleri Enstitüsü, İstanbul, 2018.

6. Eskola J, Duclos P, Schuster M, MacDonald NE. How todeal with vaccine hesitancy? Vaccine 2015;33:42154217. https://doi.org/10.1016/j.vaccine.2015.04.043

7. Salmon DA, Dudley MZ, Glanz JM, Omer SB. Vaccine hesitancy: causes, consequences, and a call to action. Vaccine 2015;33:66-71. https://doi.org/10.1016/j. vaccine.2015.09.035

8. Domek GJ, O'Leary ST, Bull S, et al. Measuring vaccine hesitancy: field testing the WHO SAGE Working Group on Vaccine Hesitancy survey tool in Guatemala. Vaccine 2018;36:5273-5281. https://doi.org/10.1016/j. vaccine.2018.07.046

9. Larson HJ, Jarrett C, Eckersberger E, Smith DMD, Paterson P. Understanding vaccine hesitancy around vaccines and vaccination from a global perspective: a systematic review of published literature, 2007-2012. Vaccine 2014;32:2150-2159. https://doi.org/10.1016/j. vaccine.2014.01.081

10. Opel DJ, Taylor JA, Mangione Smith R, et al. Validity and reliability of a survey to identify vaccine-hesitant parents. Vaccine 2011;29:6598-6605. https://doi. org/10.1016/j.vaccine.2011.06.115

11. Opel DJ, Mangione Smith R, Taylor JA, et al. Development of a survey to identify vaccine-hesitant parents: the parent attitudes about childhood vaccines survey. Hum Vaccin 2011;7:419-425. https://doi. org/10.4161/hv.7.4.14120

12. Opel DJ, Taylor JA, Zhou C, Catz S, Myaing M, Mangione Smith $\mathrm{R}$. The relationship between parent attitudes about childhood vaccines survey scores and future child immunization status: a validation study. JAMA Pediatr 2013;167:1065-1071. https://doi. org/10.1001/jamapediatrics.2013.2483
13. Ayre C, Scally AJ. Critical values for Lawshe's content validity ratio: revisiting the original methods of calculation. Meas Eval Couns Dev 2014;47:79-86. https://doi.org/10.1177/0748175613513808

14. Lawshe $\mathrm{CH}$. A quantitative approach to content validity 1. Personnel Psychology 1975;28:563-575. https://doi. org/10.1111/j.1744-6570.1975.tb01393.x

15. Helps C, Leask J, Barclay L, Carter S. Understanding non-vaccinating parents' views to inform and improve clinical encounters: a qualitative study in an Australian community. BMJ Open 2019;9:e026299. https://doi. org/10.1136/bmjopen-2018-026299

16. Cunningham RM, Kerr GB, Orobio J, et al. Development of a Spanish version of the parent attitudes about childhood vaccines survey. Hum Vaccin Immunother 2019;15:1106-1110. https://doi.org/10.1080/21645515 .2019 .1578599

Etik kurul onayı: Dicle Üniversitesi Tıp Fakültesi Girişimsel Olmayan Araştırmalar Etik Kurulu'nun 20.06.2019 tarih ve 188 sayılı kararı ile onay alınmıştır.

\section{Yazarların makaleye olan katkıları}

I.A.K., Ö.K. çalışmanın ana fikrini ve hipotezini kurgulamışlardır. İ.A.K., M.M.Ö., M.A., Y.D., F.A., S.B. teoriyi geliştirmiş ve gereç yöntem bölümünü düzenlemişlerdir. Sonuçlar kısmındaki verilerin değerlendirmesini I.A.K., M.M.Ö., Y.Y., M.K.Ç., T.D., Y.D. yapmışlardır. Makalenin tartışma bölümü İ.A.K., Ö.K. tarafından yazılmış, M.K.Ç., T.D., Y.Y., M.M.Ö., S.B., F.A. gözden geçirip gerekli düzeltmeleri yapmış ve onaylamıştır. Ayrıca tüm yazarlar çalışmanın tamamını tartışmış ve son halini onaylamıştır. 